\title{
Ameliorative effect of tamarind leaf on fluoride-induced metabolic alterations
}

\author{
Rupal A. Vasant $\cdot$ A. V. R. L. Narasimhacharya
}

Received: 19 January 2012 / Accepted: 6 March 2012/Published online: 22 March 2012

(C) The Japanese Society for Hygiene 2012

\begin{abstract}
Objectives Fluoride is a serious health hazard across several nations, and chronic intake of fluoride deranges the carbohydrate, lipid and antioxidant metabolism in general. As there are limited remedial measures to prevent fluorosis, we investigated the role of tamarind leaf as a food supplement in restoration of carbohydrate, lipid and antioxidant metabolism in fluoride-exposed albino rats.

Methods Albino rats were exposed to fluoride (100 ppm sodium fluoride) through drinking water and fed diet supplemented with tamarind leaf powder $(2.5,5$ and $10 \mathrm{~g} \%)$ for 4 weeks. Carbohydrate, lipid and antioxidant profiles were investigated in both controls and fluoride-exposed animals.

Results While 4-week exposure to fluoride elevated plasma glucose and lipid profiles, simulating diabetic and hyperlipidaemic conditions, the antioxidant defence mechanisms of fluoride-exposed rats were compromised, with elevation and decline in lipid peroxidation and high-density lipoprotein (HDL)-cholesterol, respectively. When the diet was supplemented with tender tamarind leaves (used in southern India as a replacement for tamarind or other sour food ingredients), significant improvements in carbohydrate and lipid profiles occurred as evidenced by decreased plasma glucose and lipid levels, lipid peroxidation, increased hepatic glycogen content, hexokinase activity and cholesterol excretion, with simultaneous improvement in antioxidant profiles of both hepatic and renal tissues.
\end{abstract}

R. A. Vasant · A. V. R. L. Narasimhacharya $(\bowtie)$ Laboratory for Animal Sciences, Department of Biosciences, Sardar Patel University, Sardar Patel Maidan, Vadtal Road, Satellite Campus, Vallabh Vidyanagar 388 120, Gujarat, India e-mail: narasimhacharya@spuvvn.edu
Conclusions These findings are significant in view of the need for cost-effective approaches to tackle fluorosis as an environmental hazard and use of food supplements as ameliorative measures.

Keywords Fluoride - Tamarind leaves .

Carbohydrate metabolism - Lipid metabolism .

Oxidative stress

\section{Introduction}

Fluorosis is both endemic and global, spanning several continents. Natural geological sources and more recently the advent of increased industrialization and attendant environmental pollution have contributed greatly to the increasing incidence of fluoride-related human health issues. High levels of fluoride in drinking water have become a potential health hazard all over the world, with approximately 66.62 million victims in India alone. Fluoride enters the human and animal body through drinking water and to a lesser extent through food [1]. It is well established that ingestion of higher amounts of fluoride causes metabolic disorders, by interacting with various cellular processes such as gene expression, cell cycle, proliferation and migration, respiration, metabolism, ion transport, secretion, endocytosis, apoptosis, necrosis and oxidative stress, and disrupts the antioxidant defence system in the body [2,3]. Fluoride is also reported to be hyperglycaemic, as it significantly elevated fasting blood glucose levels in laboratory animals, which was attributed to lowered insulin levels $[4,5]$. Exposure to fluoride results in generation of anion superoxide $\left(\mathrm{O}_{2}^{-}\right)$, increased $\mathrm{O}_{2}$ concentration and its downstream consequences such as hydrogen peroxide, peroxynitrite and hydroxyl radicals 
which are important in mediating the toxic effects of fluoride. Experimental evidence has indicated that exposure to fluoride results in oxidative stress both in vitro and in vivo in soft tissues such as liver, kidney, brain, lung and testes [3]. Fluoride inhibits the activities of antioxidant enzymes-superoxide dismutase, glutathione peroxidase and catalase-and reduces levels of glutathione. Glutathione reduction leads to overproduction of reactive oxygen species at the mitochondrial level, resulting in damage of cellular components. Besides, production of excessive reactive oxygen species results in oxidation of macromolecules, membrane phospholipid breakdown, lipid peroxidation, mitochondrial membrane depolarization and apoptosis [3].

Defluoridation of water is the only available option to reduce its fluoride content, but the techniques are unaffordable and beyond the reach of underprivileged communities in fluoride endemic areas across the globe. Several natural adsorbents such as red soil, charcoal, brick, fly-ash, serpentine and alum have been used to reduce the fluoride content in water [6]. Besides, novel defluoridation techniques include the use of leaves of Azadirachta indica, Ficus religiosa and Acacia catechu and tamarind seeds [7-9]. Apart from these techniques, reports also indicate the utility of plant products, for example tamarind fruit pulp, seeds of Moringa oleifera, bark extracts of Terminalia arjuna and black berry juice as possible therapeutic agents for amelioration of fluoride toxicity [10-12]. Additionally, plant metabolites such as a $43-\mathrm{kDa}$ protein isolated from Cajanus indicus, quercetin and curcumin have been shown to ameliorate fluoride-induced oxidative stress and improve the functions of liver, kidney and erythrocytes [13-16]. We recently reported the beneficial effects of seasonally available edible fruits (Limonia acidissima, Mangifera indica, Emblica officinalis) as dietary supplements/adjuncts and high-protein diets on various metabolic parameters associated with fluoride-induced alterations in body metabolism [17-21].

Tamarindus indica L. (Fabaceae; common name: tamarind) is a multipurpose tropical tree: the leaves, flowers, fruits and seeds are used to make curries, salads, stews and soups in many countries. The tender leaves of $T$. indica are traditionally used with lentils in Southern India, replacing the tamarind fruit. The leaves are also used to treat throat infections/coughs, fever, intestinal worm infections, urinary problems and liver ailments. Leaves and pulp act as a cholagogue, laxative and anticongestant and exhibit antioxidant activity in the liver in addition to their blood sugarreducing properties [22]. The leaf extracts were also shown to be antifungal and antimicrobial [23, 24]. As there are no reports concerning the utility of tamarind leaves against sodium fluoride-induced toxicity, we evaluated the efficacy of tamarind leaves in mitigating fluoride-induced metabolic alterations in carbohydrate, lipid and antioxidant profiles.

\section{Materials and methods}

Tamarindus indica leaf powder preparation and phytochemical analysis

Tender leaves of $T$. indica were collected from the Botanical Gardens of Sardar Patel University, Vallabh Vidyanagar and authenticated by our faculty taxonomist Dr. A.S. Reddy; voucher specimen was retained in the departmental herbarium (RAV \# 05). The leaves were airdried, ground to powder and stored in an airtight container. The fibre content of the leaf powder was determined [25] after petroleum ether extraction followed by acid and alkaline treatment. Phytosterol and saponin contents of the leaf powder were determined using ferric chloride-sulphuric acid and vanillin-sulphuric acid methods, respectively [26, 27]. The polyphenol and flavonoid contents were measured using Folin-Ciocalteu and vanillin sulphuric acid reagents [25]. The total ascorbic acid content (TAA) was estimated using 2,4-dinitrophenyl hydrazine reagent [28]. The total antioxidant power [ferric reducing antioxidant power (FRAP)] of the tamarind leaf powder was determined using 2,4,6-tris(2-pyridyl)-1,3,5-triazine (TPTZ) reagent [29].

\section{Animals and diet}

Colony-bred male albino rats (Charles Foster; 3 months, 200-260 g bw) housed individually in a well-ventilated animal unit $\left(26 \pm 2{ }^{\circ} \mathrm{C}\right.$, humidity $62 \%, 12$-h light/dark cycle) were supplied water ad libitum. Control animals were fed standard diet (Pranav Agro Industries, Vadodara, India), and experimental groups were provided diets with $T$. indica (Ti) leaf powder replacing the required amounts of standard diet. The research protocol followed the guidelines of the Institutional Animal Ethics Committee (MoEF/CPCSEA/Reg. 337) and were approved by the Institutional Committee for Animal Research.

After a 10-day adaptation period, 30 animals were randomly segregated into 5 groups of 6 animals each as follows: normal control (NC), normal animals without any treatment; fluoride control (FC), $100 \mathrm{ppm}$ sodium fluoride administered through drinking water; FTi I, fluorideadministered animals fed diet with $2.5 \mathrm{~g} \% \mathrm{~T}$. indica leaf powder; FTi II, fluoride-administered animals fed diet with $5 \mathrm{~g} \%$ T. indica leaf powder; FTi III, fluoride-administered animals fed diet with $10 \mathrm{~g} \%$ T. indica leaf powder (Table 1).

At the end of a 30-day period, animals were fasted overnight and sacrificed under mild ether anaesthesia. Blood was collected by cardiac puncture; plasma was separated by centrifugation and stored at low temperature. 
Table 1 Composition of the diets for animals ( $\mathrm{g} \%$ )

\begin{tabular}{lrrrrr}
\hline & NC & \multicolumn{1}{c}{ FC } & FTi I & FTi II & FTi III \\
\hline Moisture & 8.75 & 8.75 & 8.53 & 8.31 & 7.88 \\
Crude protein & 22.12 & 22.12 & 21.57 & 21.01 & 19.91 \\
Crude carbohydrate & 55.67 & 55.67 & 54.28 & 52.89 & 50.10 \\
Crude fat & 4.06 & 4.06 & 3.96 & 3.86 & 3.65 \\
Crude fibre & 3.76 & 3.76 & 3.67 & 3.57 & 3.38 \\
Mineral mixture & 5.64 & 5.64 & 5.50 & 5.35 & 5.08 \\
T. indica leaf powder & - & - & 2.50 & 5.0 & 10.0 \\
\hline
\end{tabular}

Liver and kidneys were excised and kept frozen until analysis.

Analytical procedures

Plasma glucose, hepatic glycogen, hepatic hexokinase and G-6-Pase activities

Plasma glucose levels were measured by standard kit (Eve's Inn Diagnostics, India). Hepatic glycogen was extracted with $30 \% \mathrm{KOH}$, and the yield was estimated by anthrone-sulphuric acid method [30]. Hepatic hexokinase (EC 2.7.1.1) was determined based on reduction of nicotinamide adenine dinucleotide $\left(\mathrm{NAD}^{+}\right)$through a coupled reaction with glucose-6-phosphate dehydrogenase [31]. Glucose-6-phosphatase (EC 3.1.3.9) activity was assayed by measuring the inorganic phosphate liberated from glucose-6-phosphate (G-6-P) [32].

\section{Serum marker enzymes: SGOT, SGPT, ACP, ALP} and FRAP

Serum glutamate oxaloacetate (SGOT) and pyruvate (SGPT) transaminases, and acid and alkaline phosphatases (ACP, ALP) levels were determined using standard kits (Eve's Inn Diagnostics, Baroda, India). Plasma FRAP value of the animals were measured by the method of Benzie and Strain [29].

\section{Plasma and hepatic lipid profiles}

Plasma total cholesterol (TC), HDL cholesterol (HDL-C) and triglycerides (TG) were measured by standard kits (Eve's Inn Diagnostics, India), and the plasma total lipid (TL) content was estimated by sulphophosphovanillin method [33]. Low-density lipoprotein cholesterol (LDL-C), very low-density lipoprotein cholesterol (VLDL-C) and atherogenic index (AI) were calculated [34]. Chloroformmethanol (2:1) liver extracts were used for estimation of hepatic total lipids (gravimetry), TC and TG contents (Eve's Inn Diagnostics, India).
Hepatic HMG-CoA reductase and bile acid profile

Hepatic 3-hydroxy-3-methylglutaryl-coenzyme A (HMG$\mathrm{CoA}$ ) reductase (EC 1.1.1.34) activity was measured in terms of the ratio of HMG-CoA to mevalonate [35] as HMG-CoA reductase activity is inversely proportional to the HMG-CoA/mevalonate ratio. Bile acid content was estimated using vanillin-phosphoric acid reagent [36].

\section{Faecal cholesterol and bile acid content}

The faecal cholesterol and bile acids were extracted using alkaline-methanol medium, and cholesterol was estimated [37]. A portion of the extract was acidified and used for bile acid estimation [36].

Hepatic and renal tissue lipid peroxidation and antioxidant profiles

Hepatic and renal lipid peroxidation was determined by thiobarbituric acid (TBA) assay [38]. Hepatic and renal total ascorbic acid and reduced glutathione contents were estimated using methods of Schaffert and Kingsley [28] and Jollow et al. [39]. Superoxide dismutase (SOD; EC 1.15.1.1), catalase (CAT; EC 1.11.1.6) and glutathione peroxidase (GPx; EC 1.11.1.9) activities were measured in both hepatic and renal tissues following standard methods [40-42].

Statistical evaluation

Data are presented as mean \pm standard error of the mean (SEM). One-way analysis of variance (ANOVA) with Tukey's significant difference post hoc test was used to compare differences among groups. Data were statistically analyzed using Graph Pad Prism 3.0 statistical software. $p$ values $<0.05$ were considered statistically significant.

\section{Results}

\section{Clinical observations}

No significant changes in the appearance or behaviour of animals were observed during the experiment. No mortality was recorded in controls or fluoride-exposed FTi I-III groups at the end of 30 days.

Dietary intake and growth rate of fluoride-exposed animals

Exposure to fluoride caused a significant increase in food intake but a reduction in body and liver weights in FC animals. Inclusion of Ti leaf powder in diet brought about 
significant decreases in food intake and increases in body and liver weights. These changes were more prominent when Ti leaf powder was added to the diet at $10 \mathrm{~g} \%$ level (Table 2).

Biochemical studies

\section{Antihyperglycaemic effects of T. indica in fluoride-exposed} animals

While fluoride intake significantly elevated plasma glucose and hepatic G-6-Pase levels (98.77 and $166.48 \%$,

Table 2 Effects of tamarind leaf feeding on food intake, and body and liver weights

\begin{tabular}{llll}
\hline Group & Parameter & & \\
\cline { 2 - 4 } & Food intake (g/day) & Body weight $(\mathrm{g})$ & Liver weight $(\mathrm{g})$ \\
\hline NC & $18.91 \pm 0.45$ & $245.50 \pm 2.38$ & $8.35 \pm 0.12$ \\
FC & $21.69 \pm 0.32^{\mathrm{a}}$ & $213.75 \pm 3.11^{\mathrm{a}}$ & $6.84 \pm 0.06^{\mathrm{a}}$ \\
FTi I & $21.15 \pm 0.27^{\mathrm{a}}$ & $215.92 \pm 2.87^{\mathrm{ab}}$ & $7.10 \pm 0.08^{\mathrm{a}}$ \\
FTi II & $20.50 \pm 0.15^{\mathrm{a}}$ & $217.40 \pm 1.92^{\mathrm{a}}$ & $7.25 \pm 0.10^{\mathrm{ab}}$ \\
FTi III & $18.82 \pm 0.17^{\mathrm{b}}$ & $228.08 \pm 3.05^{\mathrm{a}}$ & $7.86 \pm 0.09^{\mathrm{ab}}$ \\
\hline
\end{tabular}

Values presented as mean $\pm \operatorname{SEM}(n=6)$

${ }^{\mathrm{a}}$ Comparison with normal control group and ${ }^{\mathrm{b}}$ with fluoride control group at $p<0.05$, respectively respectively), hepatic glycogen content and hexokinase activity decreased (49.17 and $43.35 \%$, respectively). Ti leaf powder supplementation resulted in significant decline in plasma glucose and hepatic G-6-Pase levels, and both hepatic glycogen content and hexokinase activity increased in a dose-dependent manner (Table 3).

\section{SGOT, SGPT, ALP and ACP activities and FRAP value}

Fluoride consumption increased the activities of SGOT, SGPT, ALP and ACP with a reduction in plasma antioxidant capacity (FRAP value) in experimental animals, whereas Ti leaf powder-supplemented diet improved the enzymatic activities and the plasma antioxidant capacity in a dose-dependent manner (Table 4).

Antihyperlipaemic effects of $T$. indica

in fluoride-exposed animals

\section{Plasma lipid profile}

Administration of fluoride through drinking water caused hypercholesterolaemia as indicated by significant increases in plasma lipid profiles accompanied by lowered HDL-C content $(p<0.05)$. Addition of Ti leaf powder to the diet resulted in a significant reduction of fluoride-induced hypercholesterolaemia and enhanced the plasma HDL-C level (Figs. 1, 2; Table 5).

Table 3 Effects of tamarind leaf feeding on plasma glucose, hepatic glycogen content, hepatic hexokinase and glucose-6-phosphatase activities

\begin{tabular}{lrrrrr}
\hline Parameter & \multicolumn{1}{l}{ Group } & & & \\
\cline { 2 - 6 } & NC & FC & FTi I & FTi II & FTi III \\
\hline Glucose (mg/dl) & $96.47 \pm 1.34$ & $191.75 \pm 0.91^{\mathrm{a}}$ & $177.26 \pm 0.75^{\mathrm{ab}}$ & $171.42 \pm 0.59^{\mathrm{ab}}$ & $143.07 \pm 1.63^{\mathrm{ab}}$ \\
Glycogen (mg/g) & $19.91 \pm 0.24$ & $10.12 \pm 0.34^{\mathrm{a}}$ & $11.10 \pm 0.30^{\mathrm{a}}$ & $13.92 \pm 0.41^{\mathrm{ab}}$ & $18.14 \pm 0.21^{\mathrm{ab}}$ \\
Hexokinase (U/mg protein/min) & $8.35 \pm 0.19$ & $4.73 \pm 0.13^{\mathrm{a}}$ & $5.04 \pm 0.16^{\mathrm{a}}$ & $5.79 \pm 0.15^{\mathrm{ab}}$ & $6.36 \pm 0.23^{\mathrm{ab}}$ \\
G-6-Pase (U/mg protein/min) & $0.179 \pm 0.003$ & $0.477 \pm 0.002^{\mathrm{a}}$ & $0.455 \pm 0.02^{\mathrm{ab}}$ & $0.394 \pm 0.001^{\mathrm{ab}}$ & $0.333 \pm 0.002^{\mathrm{ab}}$ \\
\hline
\end{tabular}

Values presented as mean $\pm \operatorname{SEM}(n=6)$

${ }^{\mathrm{a}}$ Comparison with normal control group and ${ }^{\mathrm{b}}$ with fluoride control group at $p<0.05$, respectively

Table 4 Effects of tamarind leaf feeding on SGOT, SGPT, ACP, ALP and FRAP

\begin{tabular}{lrrrrr}
\hline Parameter & \multicolumn{1}{l}{ Group } & & \\
\cline { 2 - 6 } & \multicolumn{1}{l}{ NC } & \multicolumn{1}{c}{ FC } & \multicolumn{1}{l}{ FTi I } & FTi II & FTi III \\
\hline SGOT (U/l) & $32.81 \pm 1.09$ & $76.90 \pm 0.27^{\mathrm{a}}$ & $67.48 \pm 2.13^{\mathrm{ab}}$ & $59.07 \pm 0.52^{\mathrm{ab}}$ & $43.25 \pm 0.02^{\mathrm{ab}}$ \\
SGPT (U/l) & $39.51 \pm 0.82$ & $79.92 \pm 0.21^{\mathrm{a}}$ & $73.15 \pm 0.55^{\mathrm{ab}}$ & $67.02 \pm 0.67^{\mathrm{ab}}$ & $51.91 \pm 0.64^{\mathrm{ab}}$ \\
ALP (KA units) & $10.12 \pm 0.57$ & $28.82 \pm 0.31^{\mathrm{a}}$ & $26.71 \pm 0.49^{\mathrm{ab}}$ & $23.05 \pm 0.45^{\mathrm{ab}}$ & $19.53 \pm 0.29^{\mathrm{ab}}$ \\
ACP (KA units) & $7.03 \pm 0.15$ & $19.26 \pm 0.76^{\mathrm{a}}$ & $17.67 \pm 0.23^{\mathrm{a}}$ & $14.78 \pm 0.59^{\mathrm{ab}}$ & $11.42 \pm 0.31^{\mathrm{ab}}$ \\
FRAP ( $\mu$ mol/l) & $292.31 \pm 4.38$ & $168.12 \pm 3.41^{\mathrm{a}}$ & $206.40 \pm 5.23^{\mathrm{ab}}$ & $227.29 \pm 3.76^{\mathrm{ab}}$ & $252.63 \pm 4.12^{\mathrm{ab}}$ \\
\hline
\end{tabular}

Values presented as mean $\pm \operatorname{SEM}(n=6)$

${ }^{\mathrm{a}}$ Comparison with normal control group and ${ }^{\mathrm{b}}$ with fluoride control group at $p<0.05$, respectively 
Fig. 1 Effects of tamarind leaf feeding on the plasma lipid profiles in fluoride-administered rats

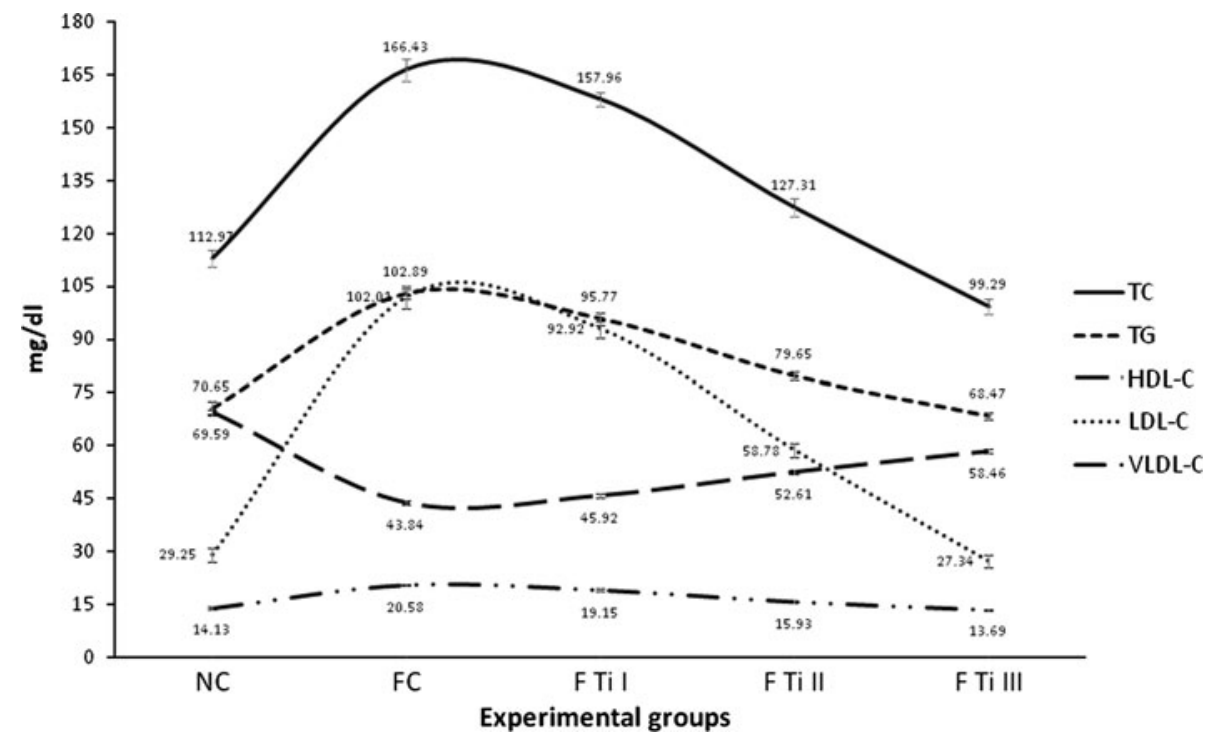

Faecal cholesterol and bile acid content

Although the FC group showed higher levels of faecal cholesterol and bile acid as compared with the NC group, the FTi I-III groups consistently registered significant increases in faecal cholesterol $(12,24,31 \%)$ and bile acid $(6,16,28 \%)$ contents (Fig. 3; Table 5).

\section{Oxidative stress markers in hepatic and renal tissues}

The FC group registered a significant increase in hepatic and renal tissue lipid peroxidation. These animals also showed a significant reduction in TAA, SOD, CAT, GSH and GPx activities. Although all three doses of Ti leaf powder reduced hepatic lipid peroxidation and enhanced levels of TAA, SOD, CAT, GSH and GPx activity, the renal lipid peroxidation and antioxidant profiles appeared to improve only with higher doses of Ti leaf powder ( 5 and 10 g \%) (Figs. 4, 5).

\section{Phytochemical analysis of $T$. indica leaves}

Phytochemical analysis of $T$. indica leaf (100 gm) revealed the presence of phytosterols $(4.89 \pm 0.08 \mathrm{~g} \%)$, saponins $(11.08 \pm 2.32 \mathrm{mg} \%)$, polyphenols $(3.85 \pm 0.59 \mathrm{~g} \mathrm{\%})$, flavonoids $(0.369 \pm 0.008 \mathrm{~g} \%)$, fibre $(1.6 \pm 0.51 \mathrm{~g} \%)$ and ascorbic acid $(0.219 \pm 0.07 \mathrm{~g} \%)$. The total antioxidant activity (FRAP) of Ti leaf powder was $1.258 \pm 0.05 \mathrm{~mol} / \mathrm{g}$.

\section{Discussion}

The present investigation clearly demonstrates the therapeutic effects of $T$. indica leaf, as it normalized carbohydrate, lipid and antioxidant profiles in fluoride-exposed 
Table 5 Effects of tamarind leaf feeding on plasma lipids, hepatic total lipids, triglycerides, total cholesterol and faecal cholesterol

\begin{tabular}{|c|c|c|c|c|c|}
\hline \multirow[t]{2}{*}{ Parameter } & \multicolumn{5}{|l|}{ Group } \\
\hline & $\mathrm{NC}$ & $\mathrm{FC}$ & FTi I & FTi II & FTi III \\
\hline $\mathrm{TL}^{\mathrm{A}}(\mathrm{mg} / \mathrm{dl})$ & $319.50 \pm 2.30$ & $471.86 \pm 3.08^{\mathrm{a}}$ & $448.99 \pm 3.89^{\mathrm{ab}}$ & $389.63 \pm 3.87^{\mathrm{ab}}$ & $346.95 \pm 3.38^{\mathrm{ab}}$ \\
\hline TL (mg/g) & $30.66 \pm 0.20$ & $56.12 \pm 0.29^{\mathrm{a}}$ & $53.16 \pm 0.29^{\mathrm{ab}}$ & $48.24 \pm 0.18^{\mathrm{ab}}$ & $35.13 \pm 0.22^{\mathrm{ab}}$ \\
\hline $\mathrm{TG}(\mathrm{mg} / \mathrm{g})$ & $11.88 \pm 0.55$ & $22.85 \pm 0.49^{\mathrm{a}}$ & $21.70 \pm 0.35^{\mathrm{a}}$ & $19.33 \pm 0.24^{\mathrm{ab}}$ & $16.02 \pm 0.19^{\mathrm{ab}}$ \\
\hline $\mathrm{TC}(\mathrm{mg} / \mathrm{g})$ & $1.90 \pm 0.04$ & $3.64 \pm 0.04^{\mathrm{a}}$ & $3.45 \pm 0.12^{\mathrm{a}}$ & $2.97 \pm 0.07^{\mathrm{ab}}$ & $2.58 \pm 0.05^{\mathrm{ab}}$ \\
\hline Faecal cholesterol $(\mathrm{mg} / \mathrm{g})$ & $1.52 \pm 0.04$ & $6.59 \pm 0.03^{\mathrm{a}}$ & $6.84 \pm 0.06^{\mathrm{ab}}$ & $6.93 \pm 0.02^{\mathrm{ab}}$ & $7.33 \pm 0.05^{\mathrm{ab}}$ \\
\hline
\end{tabular}

Values presented as mean $\pm \operatorname{SEM}(n=6)$

A Plasma lipids

${ }^{\mathrm{a}}$ Comparison with normal control group and ${ }^{\mathrm{b}}$ with fluoride control group at $p<0.05$, respectively

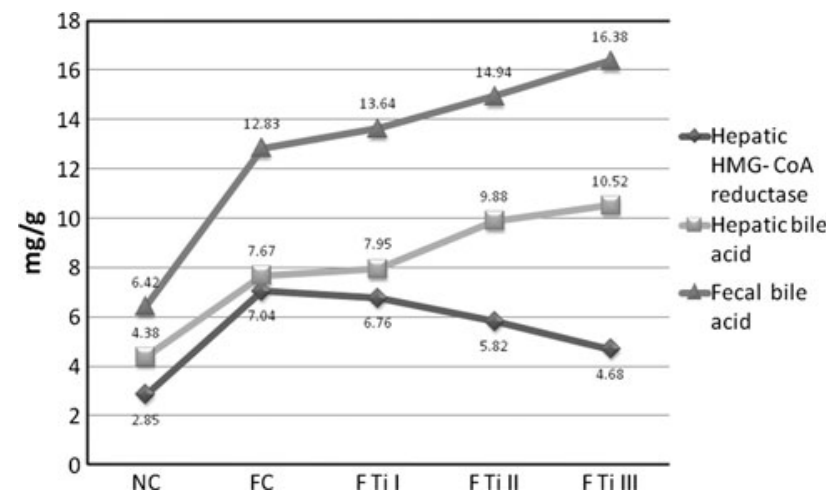

Fig. 3 Effects of tamarind leaf feeding on hepatic and faecal bile acids and hepatic HMG-CoA reductase activity in fluoride-administered rats

animals, indicating its antihyperglycaemic, antihyperlipidaemic, antiperoxidative and antioxidant properties.

Exposure to fluoride caused increased food intake, but body and liver weights declined when compared with the controls. On the other hand, inclusion of Ti leaf powder in the diet reduced feed consumption with increased body and liver weights in a dose-dependent manner, reflecting the efficacy of Ti leaf in regulating appetite and normalizing the digestion and assimilatory processes in fluoride-exposed animals.

Fluoride-exposed rats exhibited significant elevation in fasting blood glucose levels, and the hepatic glycogen content was reduced. In this group, while hepatic G-6-Pase activity increased, hexokinase activity declined. Inclusion of $T$. indica leaf powder in the diet resulted in substantial lowering of blood glucose levels and hepatic G-6-Pase activity along with improvements in hepatic glycogen content and hexokinase activity in fluoride-exposed animals. The decline in hexokinase activity in fluorideadministered animals could be due to lowered insulin levels [5]. The increase in hexokinase activity in FTi I-III groups (Table 3) on the other hand could be due to an insulin restoratory potential of $\mathrm{Ti}$ leaves. These antihyperglycaemic activities of Ti leaves could be ascribed to the secondary metabolites (polyphenols, flavonoids, phytosterols, saponins, ascorbic acid and fibre) present in $\mathrm{Ti}$ leaves. Polyphenols are known to inhibit glucose absorption in the gut, inhibit peripheral tissue glucose uptake by glucose transporters [43], protect pancreatic $\beta$ cells and inhibit insulin resistance [44, 45]. Flavonoids are reported to possess antidiabetogenic potential. This purported antidiabetogenic activity of flavonoids was attributed to an increase in pancreatic secretion of insulin from $\beta$ cells or its release from bound insulin [46-48]. Saponins have also been shown to possess hypoglycaemic properties owing to their stimulatory effects on $\beta$ cells, suppressive effects on glucose transport from stomach to small intestine and inhibition of glucose transport across the brush border of small intestine [49]. Besides phytosterols, ascorbic acid and dietary fibre also participate in glucose metabolism and control insulin secretion [50-52]. It appears therefore that the phytometabolites present in Ti leaves may have contributed individually or synergistically to the declined levels of glucose and hepatic G-6-Pase while enhancing the activity of hexokinase and improving glycogen content. While exposure to fluoride significantly elevated SGOT, SGPT, ALP and ACP activities, indicating compromised liver functions, Ti leaf-fed animals exhibited a reverse trend in a dose-dependent manner, indicating restoration of hepatic functions.

Exposure to fluoride significantly elevated the levels of TL, TC, TG, LDL-C and VLDL-C, and consequently the atherogenic index increased in the FC group (Fig. 2). The increased lipid profiles in FC clearly suggest that not only high-fat diets but also agents such as fluoride could be a possible source of hyperlipidaemia and atherogenesis in fluoride endemic areas. A significant reduction in plasma and hepatic lipid profiles and atherogenic index together with an increase in HDL-C levels of FTi I-III groups indicate the potential of $\mathrm{Ti}$ leaf as a food supplement in amelioration of fluoride-induced dyslipidaemia. 


\section{Tissue lipid peroxidation}

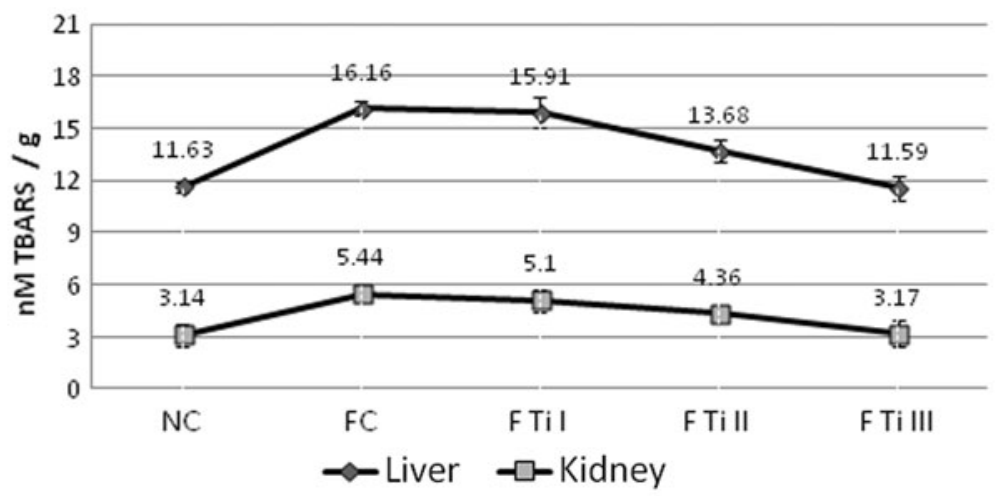

Non- enzymatic antioxidants
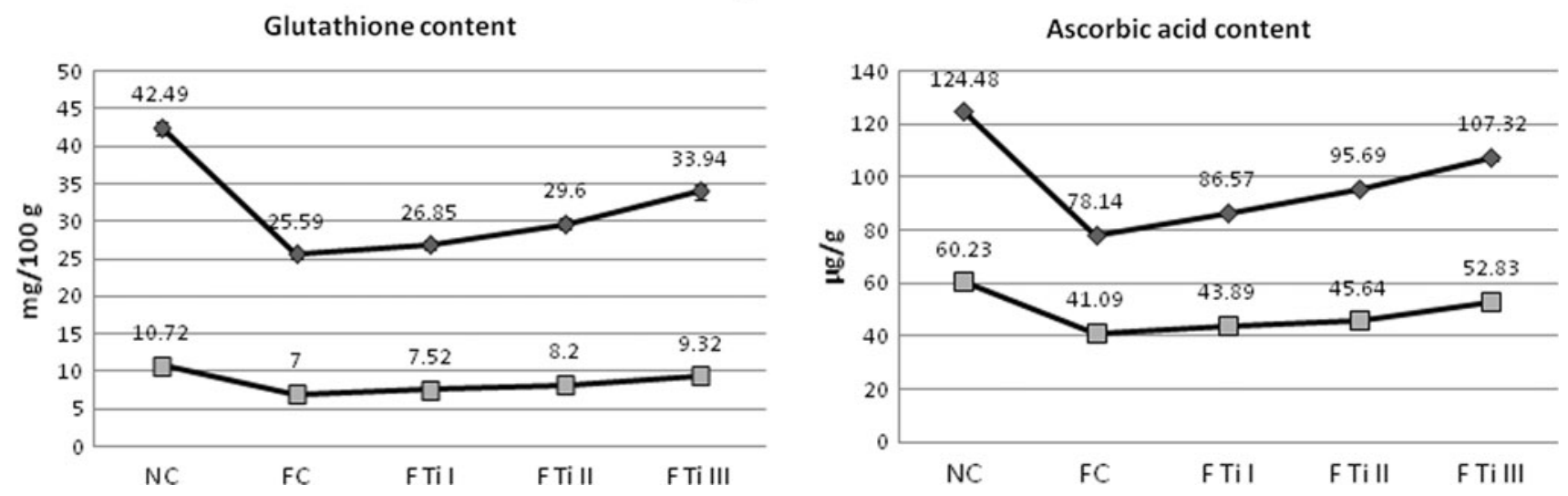

Fig. 4 Effects of tamarind leaf feeding on hepatic and renal tissue lipid peroxidation and non-enzymatic antioxidants in fluoride-administered rats

The lowered plasma and hepatic cholesterol and increased excretion of faecal cholesterol and bile acids in FTi I-III groups could be due to the fibre content of Ti leaf, as dietary fibre is found to increase cholesterol excretion by interfering with enterohepatic circulation of cholesterol $[53,54]$. Besides, both phytosterols and saponins present in $\mathrm{Ti}$ leaf also could be responsible for the antihypercholesterolaemic effects. Phytosterols are known to inhibit cholesterol absorption from the intestine due to their greater hydrophobicity and greater affinity for micelles than cholesterol itself, displacing intestinal cholesterol [55]. A number of studies clearly indicated that saponins are potent antihypercholesterolaemic agents in both animals and humans, as they are capable of precipitating cholesterol from micelles and interfere with enterohepatic circulation of bile acids, making them unavailable for intestinal absorption, leading to a reduction in plasma and hepatic cholesterol levels [49]. An increased HMG-CoA reductase activity in Ti-fed animals compared with that of the FC group appears to constitute a metabolic alteration occurring in hepatic tissue as a response to increased elimination of cholesterol through bile acids. This increase in HMG-CoA reductase activity in Ti-fed groups implies an effect of Ti leaf addition to diet on cholesterol synthesis in fluoride-exposed animals to compensate for the loss of cholesterol through faecal excretion.

While exposure to fluoride elevated the levels of plasma and hepatic TG, the FTi I-III groups exhibited a significant decline in plasma and hepatic TG, indicating the hypotriglyceridaemic effect of Ti leaf. Both dietary fibre and saponins are reported to lower TG through increased hepatic lipogenesis and by inhibiting pancreatic lipase activity $[49,53]$. Furthermore, the decline in VLDL-C levels in Ti-treated groups could be directly correlated to a decline in TG levels of these groups, as it is well established that VLDL particles are the main transporters of TG in plasma [56]. Thus, the significant reduction in both TG and VLDL-C in Ti-administered groups indicates possible synergistic or additive effects of both fibre and saponins on the one hand, and on the other, the effects of phytosterols of the Ti leaf on TG metabolism through decreased absorption of dietary cholesterol. In this context, although the TC:TG ratio in all three groups (i.e. FTi I-III) decreased marginally, the TC:HDL-C and TG:HDL-C 


\section{Enzymatic antioxidants}
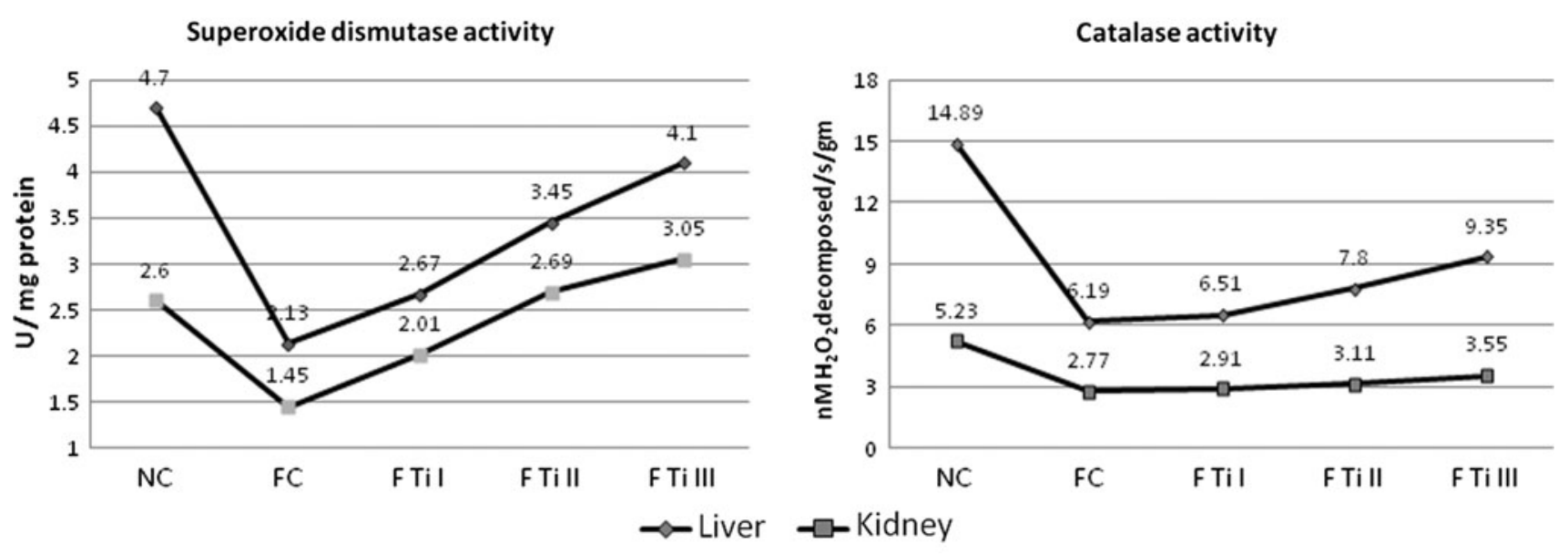

Glutathione peroxidase activity

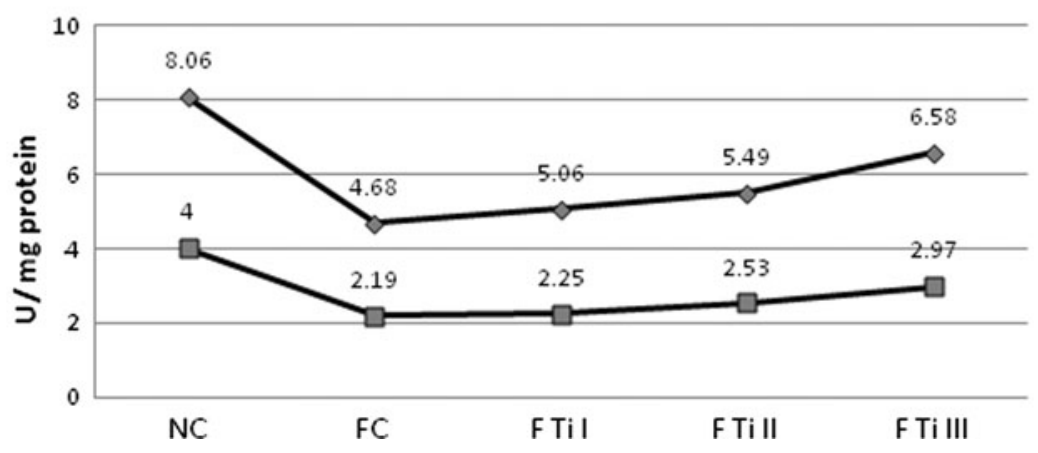

Fig. 5 Effects of tamarind leaf feeding on hepatic and renal enzymatic antioxidants in fluoride-administered rats

ratios reduced significantly in a dose-dependent manner, suggesting improvements in hyperlipidaemic status of fluoride-exposed animals. Presently observed high levels of plasma HDL-C in FTi I-III groups could be related to the ascorbic acid and flavonoid content of Ti leaf, as both ascorbic acid and flavonoids have been reported to increase HDL-C content $[57,58]$. An overall significant decline in lipid profiles and the atherogenic index of Ti leaf powderfed fluoride-intoxicated rats thus indicates the composite antihyperlipidaemic effects of saponins, phytosterols, dietary fibre, polyphenols, flavonoids and ascorbic acid.

Oxidative stress generates reactive oxygen speciessuperoxide $\left(\mathrm{O}_{2}^{-}\right)$, hydrogen peroxide, peroxynitrite and hydroxyl radicals-and, when free-radical production is excessive, oxidative damage occurs, compromising the antioxidant defence systems. This results in chemical injury to lipids, proteins and DNA. In various clinical conditions such as diabetes, hypercholesterolaemia, cardiovascular and neurodegenerative disorders, and cancer, oxidative stress plays a major role in pathogenesis of these diseases [59]. Fluoride intake is known to cause oxidative stress, and its relationship with free-radical generation is well studied in various biological systems [2-4]. In the present context, fluoride-exposed rats exhibited elevated levels of hepatic and renal tissue lipid peroxidation with significant decline in hepatic and renal antioxidant profiles. $\mathrm{Ti}$ leaf powder as a supplement reversed the fluorideinduced lipid peroxidation in a dose-dependent manner (i.e. $10 \mathrm{~g} \%<5 \mathrm{~g} \%<2.5 \mathrm{~g} \%$ doses). Ascorbic acid is an important natural antioxidant that eliminates reactive oxygen species and reduces oxidative stress [51]. Presently, in both hepatic and renal tissues, the TAA improved substantially upon feeding with Ti leaf powder. Superoxide dismutase converts superoxide radicals into less harmful products such as hydrogen peroxide and decreases superoxide radical concentration $[60,61]$, whereas catalase reduces hydrogen peroxides and provides protection to tissues. While in fluoride-exposed rats both SOD and CAT activities were reduced significantly, $T$. indica leaf powder addition to the diet accelerated the activities of both SOD and CAT in FTi I-III animals. Glutathione peroxidase (GPx) utilizes the glutathione content for decomposition of $\mathrm{H}_{2} \mathrm{O}_{2}$ or other organic hydroperoxides to non-toxic products [62]. Both hepatic and renal glutathione content and 
glutathione peroxidase activity decreased significantly in fluoride-exposed rats; addition of T. indica leaf powder to the diet resulted in considerable improvement in both hepatic and renal glutathione content and glutathione peroxidase activity. Polyphenols and flavonoids, besides being antihyperlipidaemic, are also reported to be important antioxidant molecules that decrease tissue lipid peroxidation and reduce oxidative stress [43, 63]. The improved antioxidant status with significant reduction in tissue lipid peroxidation in fluoride-exposed Ti leaf powder-fed rats could be attributed to the phytoconstituents of $\mathrm{Ti}$ leaf powder. This contention also derives support from the fact that tamarind leaf is a potential source of antioxidants, as revealed by its antioxidant capacity $(1.258 \mathrm{~mol} / \mathrm{g})$ and the increased FRAP values in the FTi I-III groups (206.40, 227.29 and $252.63 \mu \mathrm{mol} / \mathrm{l})$ as compared with that of the fluoride controls $(168.12 \mu \mathrm{mol} / \mathrm{l})$.

Thus, the present study clearly indicates the potential of $T$. indica leaves as an antihyperglycaemic, antihyperlipidaemic, antiperoxidative and antioxidant agent in fluorideinduced toxicity. The improvement in carbohydrate, lipid and antioxidant metabolisms could be due to the multi-factorial effects of secondary metabolites present in tamarind leaves. On the other hand, these metabolites could also have acted individually or synergistically to reduce the oxidative stress caused by consumption of fluoride. It is pertinent to note here that, traditionally, tender tamarind leaves are used in food preparations in India with no known toxic effects. Therefore, in light of our observations, we conclude that tamarind leaves could be used as a component in foods to promote the health of people living in endemic fluorotic areas as a means to ameliorate fluoride-induced ailments.

Acknowledgments R.A.V. is grateful to the University Grants Commission, New Delhi, India for financial support in the form of a Research Fellowship.

Conflict of interest The authors declare that there are no conflicting or competing financial interests.

\section{References}

1. Susheela AK. A treatise on fluorosis. 3rd ed. New Delhi: Fluorosis Research and Rural Development Foundation; 2007.

2. Strunecka A, Patocka J, Blaylock RL, Chinoy NJ. Fluoride interactions: from molecules to disease. Curr Signal Transduct Ther. 2007;2:190-213.

3. Barbier O, Arreola-Mendoza L, Razo LMD. Molecular mechanisms of fluoride toxicity. Chem Biol Interact. 2010;188:319-33.

4. Rupal AV, Dhrutigna RK, Krutika LB, Narasimhacharya AVRL. Therapeutic benefits of glibenclamide in fluoride intoxicated diabetic rats. Fluoride. 2010;43:141-9.

5. Garcia-Montalvo EA, Reyes-Perez H, Del-Razo LM. Fluoride exposure impairs glucose tolerance via decreased insulin expression and oxidative stress. Toxicology. 2009;263:75-83.
6. Chidambaram S, Ramanathan AL, Vasudevan S. Fluoride removal studies in water using natural materials. Water SA. 2003; 29(3):339-43.

7. Jamode AV, Sapkal VS, Jamode VS. Defluoridation of water using inexpensive adsorbents. J Ind Inst Sci. 2004;84:163-71.

8. Murugan M, Subramanian E. Application of Aloe vera (Indian Aloe) a plant material for defluoridation. Ind J Environ Prot. 2002;22(9):1034-9.

9. Murugan M, Subramanian E. Studies on defluoridation of water by tamarind seed, an unconventional biosorbent. J Water Health. 2006;4(4):453-61.

10. Ranjan R, Swarup D, Patra RC, Chandar V. Tamarindus indica L and Moringa oleifera $\mathrm{M}$ extract administration ameliorates fluoride toxicity in rabbits. Ind J Exp Biol. 2009;47:900-5.

11. Sinha M, Manna P, Sil PC. Aqueous extract of the bark of Terminalia arjuna plays a protective role against sodium-fluoride induced hepatic and renal oxidative stress. J Nat Med. 2007;61: 251-60.

12. Hassan HA, Yousef MI. Mitigating effects of antioxidant properties of black berry juice on sodium fluoride induced hepatotoxicity and oxidative stress in rats. Food Chem Toxicol. 2009;47: 2332-7.

13. Manna P, Sinha M, Sil PC. A $43 \mathrm{kD}$ protein isolated from the herb Cajanus indicus L attenuates sodium fluoride induced hepatic and renal disorders in vivo. $\mathrm{J}$ Biochem Mol Biol. 2007;40:382-95.

14. Nabavi SM, Nabavi SF, Eslami S, Moghaddam AH. In vivo protective effects of quercetin against sodium fluoride-induced oxidative stress in the hepatic tissue. Food Chem. 2012;132: 931-5.

15. Nabavi SF, Moghaddam AH, Eslami S, Nabavi SM. Protective effects of curcumin against sodium fluoride-induced toxicity in rat kidneys. Biol Trace Elem Res. 2011. doi:10.1007/s12011011-9194-7.

16. Nabavi SF, Nabavi SM, Abolhasani F, Moghaddam AH, Eslami S. Cytoprotective effects of curcumin on sodium fluoride-induced intoxication in rat erythrocytes. Bull Environ Contam Toxicol. 2011. doi:10.1007/s00128-011-0495-5.

17. Rupal AV, Narasimhacharya AVRL. Alleviation of fluoride induced hepatic and renal oxidative stress in rats by the fruit of Limonia acidissima. Fluoride. 2011;44(1):14-20.

18. Rupal AV, Narasimhacharya AVRL. Amelioration of fluoride induced oxidative stress by Mangifera indica $\mathrm{L}$ fruit. Spatula DD. 2011;1(4):181-8.

19. Rupal AV, Narasimhacharya AVRL. A multigrain protein enriched diet mitigates fluoride toxicity. J Food Sci Technol. 2011. doi:10.1007/S13197-011-0367-3.

20. Rupal AV, Narasimhacharya AVRL. Antihyperglycemic and antihyperlipemic effects of Mangifera indica L. in fluoride induced toxicity. Pharmacologyonline. 2011;3:265-74.

21. Rupal AV, Narasimhacharya AVRL. Alleviatory effects of Emblica officinalis $\mathrm{G}$. as a food supplement in fluoride induced hyperlipemia and oxidative stress. Int J Pharm Pharm Sci. 2012. In press.

22. El-Siddig K, Gunasena HPM, Prasada BA, Pushpkumara DKNG, Ramana KVR, Vijayanand P, et al. Tamarind: Tamarindus indica L. Southampton: Southampton Centre for Underutilized Crops; 2006.

23. Doughari JH. Antimicrobial activity of Tamarindus indica Linn. Trop J Pharm Res. 2006;5(2):597-603.

24. Abubakar MG, Yerima MB, Zahriya AG, Ukwuani AN. Acute toxicity and antifungal studies of ethanolic leaves, stem and pulp extract of Tamarindus indica. Res J Pharm Biol Chem Sci. 2010;1(4):104-11.

25. Thimmaiah SK. Standard methods of biochemical analysis. New Delhi: Kalyani Publishers; 1999. p. 264, 293-8. 
26. Goad LJ, Akihisa T. Analysis of sterols, 1st edn. London: Blackie Academic and Professional; 1997. p. 423-5.

27. Ebrahimzadeh H, Niknam V. A revised spectrophotometric method for determination of triterpenoid saponins. Indian Drugs. 1998;35:379-81.

28. Schaffert RR, Kingsley GR. A rapid, simple method for the determination of reduced, dehydro-, and total ascorbic acid in biological material. J Biol Chem. 1955;212:59-68.

29. Benzie IFF, Strain JJ. The ferric reducing ability of plasma (FRAP) as a measure of antioxidant power: the FRAP assay. Ann Biochem. 1996;239:70-6.

30. Seifter S, Dayton S, Novic B, Muntwyler E. Estimation of glycogen with anthrone reagent. Arch Biochem. 1950;25:191-200.

31. Brandstup N, Kirk JE, Bruni C. Determination of hexokinase in tissues. J Gerontol. 1957;12:166-71.

32. Baginsky ES, Foa PP, Zad B. Glucose-6-phosphatase. In: Bergemeyer HU, editor. Methods of enzymatic analysis. 2nd ed. New York: Academic; 1974. p. 788-92.

33. Frings CS, Fendley TW, Dunn RT, Queen CA. Improved determination of total serum lipids by the sulfo-phospho-vanillin reaction. Clin Chem. 1972;18:673-4.

34. Friedewald WT, Levy RI, Fredrickson DS. Estimation of the concentration of low-density lipoprotein cholesterol in plasma, without use of the preparative ultracentrifuge. Clin Chem. 1972;18:499-502.

35. Rao AV, Ramakrishnan S. Indirect assessment of hydroxymethylglutaryl CoA reductase (NADPH) activity in liver tissue. Clin Chem. 1975;21(10):1523-5.

36. Snell FD, Snell CT. Colorimetric methods of analysis, vol. 4. New York: D. Van Nostrand; 1953. p. 371-7.

37. Kaiek HD, Stellaard F, Kruis W, Paumgartner G. Detection of increased bile acid content in simple stool samples. Clin Chim Acta. 1984;140:85-90.

38. Ohkawa H, Ohishi N, Yagi K. Assay for lipid peroxides in animal tissues by thiobarbituric acid reaction. Ann Biochem. 1979;95: 351-8.

39. Jollow DJ, Mitchell JR, Zampaglione N, Gillette JR. Bromobenzene-induced liver necrosis. Protective role of glutathione and evidence for 3,4-bromobenzene oxide as the hepatotoxic metabolite. Pharmacology. 1974;11:151-69.

40. Kakkar P, Das B, Viswanathan PN. A modified spectrophotometric assay of superoxide dismutase. Ind J Biochem Biophys. 1984;2:130-2.

41. Aebi H. Catalase, 2nd edn. In: Bergmeyer, editor. Methods of enzymatic analysis, vol 2. New York: Academic; 1974. p. 673-84.

42. Flohe L, Gunzler WA. Assay of glutathione peroxidase. In: Methods of enzymology. New York: Academic; 1984. p. 114-21.

43. Pandey KB, Rizvi SI. Current understanding of dietary polyphenols and their role in health and disease. Curr Nutr Food Sci. 2009;5:249-63.

44. Zunino SJ, Storms DH, Stephensen CB. Diets rich in polyphenols and vitamin $\mathrm{A}$ inhibit the development of type I autoimmune diabetes in non-obese diabetic mice. J Nutr. 2007;137:1216-21.

45. Meydani M, Hasan ST. Dietary polyphenols and obesity. Nutrients. 2010;2:737-51.
46. Sharma SB, Nasir A, Prabhu KM, Dev G, Murthy PS. Hypoglycemic and hypolipidemic effects of ethanolic extracts of seeds of Eugenia jambolana in alloxan induced diabetic model of rabbits. J Ethnopharmacol. 2003;85:201-6.

47. Sharma B, Balomajumder C, Roy P. Hypoglycemic and hypolipidemic effects of flavonoid rich extract from Eugenia jambolana seeds on streptozotocin induced diabetic rats. Food Chem Toxicol. 2008;46:2376-83.

48. Sridhar SB, Sheetal UD, Pai MRSM, Shastri MS. Preclinical evaluation of the antidiabetic effect of Eugenia jambolana seed powder in streptozotocin diabetic rats. Braz $\mathrm{J}$ Med Biol Res. 2005;38(3):463-8.

49. Francis G, Kerem Z, Makkar HPS, Becker K. The biological action of saponins in animal systems: a review. $\mathrm{Br} \mathrm{J}$ Nutr. 2002;88:587-605.

50. Misawa E, Tanaka M, Nomaguchi K, Yamada M, Toida T, Takase $\mathrm{M}$, et al. Administration of phytosterols isolated from Aloe vera gel reduce visceral fat mass and improve hyperglycemia in Zucker diabetic fatty (ZDF) rats. Obes Res Clin Pract. 2008;2:239-45.

51. Oguntibeju OO. The biochemical, physiological and therapeutic roles of ascorbic acid. Afr J Biotechnol. 2008;7:4700-5.

52. Anderson JW, Akanji AO. Dietary fiber-an overview. Diabetes Care. 1991;14:1126-31.

53. Arjmandi BH, Ahn J, Nathani S, Reeves RD. Dietary soluble fiber and cholesterol affect serum cholesterol concentration, hepatic portal venous short-chain fatty acid concentrations and fecal sterol excretion in rats. J Nutr. 1992;122:246-53.

54. Moundras C, Behr SR, Remesy C, Demigne C. Fecal losses of sterols and bile acids induced by feeding rats guar gum are due to greater pool size and liver bile acid secretion. J Nutr. 1997;127:1068-76.

55. Kritchevsky D, Chen SC. Phytosterols-health benefits and potential concerns: a review. Nutr Res. 2005;25:413-28.

56. Howell TJ, MacDaugall DE, Jones PJH. Phytosterols partially explain differences in cholesterol metabolism caused by corn or olive oil feeding. J Lipid Res. 1998;39:892-900.

57. Daniel RS, Devi KS, Augusti KT, Sudhakaran NCR. Mechanism of action of antiatherogenic and related effects of Ficus bengalensis Linn. flavonoids in experimental animals. Ind J Exp Biol. 2003;41(4):296-303.

58. Vinson JA, Hu SJ, Jung S, Stanski AM. A citrus extract plus ascorbic acid decreases lipids, lipid peroxides, lipoprotein oxidation susceptibility, and atherosclerosis in hypercholesterolemic hamsters. J Agric Food Chem. 1998;46(4):1453-9.

59. Halliwell B. The wanderings of a free radical. Free Radic Biol Med. 2009;46:531-42.

60. Robinson BH. The role of manganese superoxide dismutase in health and disease. J Inherit Metab Dis. 1998;21:598-603.

61. Brioukhanov AL, Netrusov AI. Catalase and superoxide dismutase: distribution, properties, and physiological role in cells of strict anaerobes. Biochemistry. 2004;69:949-62.

62. Bruce A, Freeman D, James C. Biology of disease-free radicals and tissue injury. Lab Invest. 1982;47:412-26.

63. Yao LH, Jiang YM, Shi J, Tomás-Barberán FA, Datta N, Singanusong R, et al. Flavonoids in food and their health benefits. Plant Food Hum Nutr. 2004;59:113-22. 